\title{
Biogeography and diversification dynamics of the African woodpeckers
}

Jérôme Fuchs ${ }^{1,3,}{ }^{*}$, Jean-Marc Pons ${ }^{1}$, Rauri C.K. Bowie ${ }^{2,3}$

${ }^{1}$ UMR7205 Institut de Systématique, Evolution, Biodiversité CNRS MNHN UPMC EPHE, Sorbonne Universités, Muséum National d'Histoire Naturelle, CP 51, 57 rue Cuvier, F-75231 Paris Cedex 05, France.

${ }^{2}$ Museum of Vertebrate Zoology and Department of Integrative Biology, 3101 Valley Life Science Building, University of California, Berkeley, CA 94720-3160, USA

${ }^{3}$ DST/NRF Centre of Excellence at the Percy FitzPatrick Institute, University of Cape Town, Rondebosch 7701, South Africa

* Corresponding Author: Jérôme Fuchs. UMR7205 Institut de Systématique, Evolution, Biodiversité CNRS MNHN UPMC EPHE, Sorbonne Universités, Muséum National d'Histoire Naturelle, CP 51, 57 rue Cuvier, F-75231 Paris Cedex 05, France. Email : fuchs@mnhn.fr 
The dynamics of species accumulation of African terrestrial vertebrates over time remains underexplored in comparison with those in the New World, despite Africa hosting about 25\% of the world's avian diversity. This lack of knowledge hampers our understanding of the fundamental processes that drive biodiversity and the dynamics of speciation. To begin to address this gap, we reconstructed species-level phylogenies of two unrelated clades of African woodpeckers (12 species of Geocolaptes/Campethera and 13 species of Chloropicus/ Mesopicos/ Dendropicos/Ipophilus) that diverged from their closest Indo-Malayan relatives at similar times. Our results demonstrate that the current taxonomy is misleading: three (Campethera, Dendropicos and Mesopicos) out of four polytpic genera/subgenera are not monophyletic. Our results also show that current estimates of diversity at the species level are significantly understated, as up to 18 species for the 'Campethera clade' and 19 for the 'Dendropicos clade' could be recognized. The first splits within both clades involve species that are largely restricted to the Guineo-Congolian biogeographic regions, followed by later adaptations to particular habitats (forest versus savannah) and colonisation of other regions (e.g. Southern Africa), each of which occurred multiple times in both clades. Assuming a conservative species delimitation scheme, our results indicate that diversification rates are decreasing through time for both clades. Applying a more extreme species recognition scheme (18 and 19 species for the Campethera and Dendropicos clades, respectively), our results support a decrease in diversification rates only for the Dendropicos clade and thus underline the importance of the number of species included in our diversification analyses. Greater ecological diversity of the Campethera clade where multiple species exhibit either an arboreal or terrestrial foraging strategy might explain the constant diversification rates through time we found under the eighteen species scheme.

Key words: Picidae; Africa; phylogeny; biogeography; diversification rates 


\section{INTRODUCTION}

Sub-Saharan Africa hosts a substantial proportion of the world's avian diversity with up to 2500 species and 526 genera (311 endemic; Newton 2003). Although some detailed phylogeographic studies have been performed within species or species complexes (e.g. Bowie et al. 2004a, b, 2006, Fuchs et al. 2011a, b, in press, Fuchs and Bowie 2015, Marks 2010, Oatley et al. 2012), the relationships among congeneric species from speciose bird genera, and thus the broad scale biogeographic patterns in Africa, remain poorly understood (but see Nguembock et al. 2008, Njabo et al. 2008, Outlaw et al. 2010, Voelker et al. 2010, 2014, 2016). Similarly, the dynamics of species accumulation through time remain understudied in African terrestrial vertebrates (Zimkus et al. 2014), especially compared to their counterparts in the Neotropical or Nearctic realms (e.g. Barker et al. 2012, Smith et al. 2014). This lack of knowledge clearly hampers our understanding of the fundamental processes that drive the formation of biodiversity, persistence of biodiversity, and the dynamics of speciation in Africa.

The African woodpeckers (Aves: Picinae) consist of two unrelated species assemblages: Campethera/Geocolaptes - hereafter referred to as the Campethera clade; and Dendropicos/Chloropicus/Mesopicos/Ipophilus - hereafter referred to as the Dendropicos clade. Characterized by a similar richness of species (12 species for the Campethera clade; 13 species for the Dendropicos clade; Dickinson and Remsen Jr 2013), the two assemblages have similar spatiotemporal origins, as both lineages split from their respective Indo-Malayan relatives between 7-8.5 million years ago (mya; Fuchs et al. 2007).

Fuchs et al. (2007) found a strongly supported sister-group relationship between two Campethera species (C. caroli and C. nivosa) and Geocolaptes, a monotypic genus endemic to South Africa. Yet, Campethera caroli and C. nivosa are thought to be closely related, as they were both previously included in the genus Stictopicus (Wolters 1975-82). A recent supermatrix analyses suggested that Geocolaptes could possibly be nested in Campethera (Dufort 2016). Yet, the prevalence of missing data (68\% missing), quality of the generated data (e.g. ND2 sequence of Picus miniaceum Genbank KT455636 contains 74 IUPAC uncertainty codes), and strong variation in support values for the node involving Geocolaptes (34\% bootstrap in species tree analyses, $68 \%$ bootstrap in maximum likelihood analyses and a posterior probability of 1.0 in Bayesian inferences) make it difficult to assess this result. The remaining Campethera species are traditionally grouped in three species complexes: 'nubica', 
consisting of nubica, punctuligera, bennettii including scriptoricauda; 2) 'abingoni', consisting of abingoni, notata and mombassica; and 3) 'caillautii' consisting of caillautii including permista - and maculosa). Finally, C. tullbergi, including taeniolaema, has no clear affinities with any of the three superspecies. Each of the three superspecies have parapatric distributions that match the positioning of biogeographic realms in Africa (e.g. Sudanian sensu Linder et al 2012 for C. punctuligera). Consequently, taxonomists have widely debated the species limits of some of the superspecies, with different authors considering some taxa either as species or subspecies. For example, the Mombassa Woodpecker C. mombassica, restricted to the coastal forest of Kenya, Somalia and northeastern Tanzania, has been considered a subspecies of the Golden-tailed Woodpecker C. abingoni (Peters 1948). The permista subspecies, restricted to the Lower Guinea Forest Block, of the Green-backed Woodpecker (C. cailliautii) is sometimes considered to be distinct at the species level from the savannah subspecies group (C. cailliautii sensu stricto) (Peters 1948), although most authorities consider it as a subspecies (e.g. Winkler and Christie 2002, Dickinson and Remsen Jr 2013). Finally, Reichenow's Woodpecker C. scriptoricauda has historically been considered conspecific with Bennett's Woodpecker C. bennettii (Dickinson and Remsen Jr 2013) or even with an extended Nubian Woodpecker (Peters 1948). Our current knowledge about the phylogenetic relationships within the Campethera/Geocolaptes clade is very limited.

The limits of the Dendropicos clade have always been well-defined, with the exception of one species, Dendropicos obsoletus. The latter species is sometimes included in the genus Dendrocopos but recent molecular data have shown it to be nested within Dendropicos (Fuchs and Pons 2015). Currently, four genera are recognized within the Dendropicos clade (Dickinson and Remsen Jr 2013): 1) Dendropicos (six species, elachus, poecilolaemus, abyssinicus, fuscescens, gabonensis, stierlingi); 2) Chloropicus (three species, namaquus, xantholophus, pyrrhogaster); 3) Mesopicos (three species, elliotii, griseocephalus, goertae); and 4) Ipophilus (monotypic, obsoletus). The current taxonomic scheme represents one of many schemes that have been proposed for this clade; some authors recognize only one genus (Dendropicos, Winkler and Christie 2002), whereas others consider the species elliotii to be sufficiently distinct to be retained in its own genus Polipicus (Wolters 1975-82). Sampling four species representing three genera, Fuchs et al. (2007) found that the resulting topology suggested sister-group relationships between $M$. elliotii and Dendropicos and between M. griseocephalus and Chloropicus. Most other studies (Webb and Moore 2005, 
Benz et al. 2006) have included only one species for the Dendropicos clade (e.g. M. goertae in Benz et al. 2006). The species limits within many species complexes of the Dendropicos clade remain debated. Several authors have consistently recognized up to three subspecies within the clade (e.g. Dendropicos gabonensis lugubris, Mesopicos elliotii johnstoni, Mesopicos griseocephalus spodocephalus) as being distinct at the species level (e.g. Winkler and Christie 2002).

A comparison of the diversification dynamics of the Campethera and Dendropicos clades could help formulate an initial set of hypotheses regarding the parameters driving the diversification of African terrestrial vertebrates which mainly occupy primary forest and woodland habitats. These woodpeckers are particularly suitable as exemplar clades for such a study as several species complexes have similar distribution patterns (Figure 1). Testing such hypotheses requires a robust phylogeny with thorough sampling of taxa. Yet, knowledge of the phylogenetic relationships among species/subspecies within the Campethera and the Dendropicos clades is currently very limited, given that all previous studies were specifically designed to resolve the higher-level relationships among woodpeckers and thus were not exhaustive at the species level (Webb and Moore 2005, Benz et al. 2006, Fuchs et al. 2007, 2013). In the present study, we used mitochondrial and nuclear DNA sequences to: 1) resolve the phylogenetic relationships among African woodpeckers; 2) shed light on their historical biogeography; and 3) compare their diversification history in space and time, that is, to determine whether species accumulation patterns between the two clades are similar?

\section{MATERIAL AND METHODS}

\section{Sampling design}

We sampled all recognized species within the Campethera and Dendropicos clades, and also several subspecies whose species status is subject to debate by taxonomists (e.g. Campethera caillautii permista, C. tullbergi taeniolaema) (Dickinson and Remsen Jr 2013). In addition to fresh tissue samples $(n=68)$, we used 30 skin scrapes (i.e. toe pad samples) collected from museum specimens (Supplementary Table 1). Our current sampling for widely distributed species also encompasses all the primary lineages found in our ongoing studies on the phylogeography of African woodpeckers (Campethera nivosa and C. caroli, Fuchs and Bowie 2015; Dendropicos fuscescens and D. griseocephalus, Fuchs and Bowie, unpubl. data). As proximate outgroups, we used sequences from a representative set of other Picinae genera 
( $\mathrm{n}=28$, Table 1) (e.g. Webb and Moore 2005, Benz et al. 2006, Fuchs et al. 2007, 2008). We rooted our tree using sequences from a piculet (Sasia ochracea) (Swierczewski and Raikow 1981, Webb and Moore 2005, Benz et al. 2006, Fuchs et al. 2006, 2007, 2013).

\section{Laboratory protocols}

We extracted DNA from blood and tissue (muscle, liver, feather) using the Qiagen extraction kit (Qiagen, Valencia, CA) following the manufacturer's protocol.

DNA was extracted from skin scrapes off museum specimens (toe-pads) in special clean rooms dedicated to historical DNA to help minimize the possibility of crosscontamination of the museum samples by fresh DNA. We used the same protocol as for the modern samples but added $20 \mathrm{ul}$ of dithiothreitol (DTT, $0.1 \mathrm{M}$ ) to facilitate the digestion of these tissues. We used very stringent protocols to ensure that DNA sequences obtained from these historical specimens represent genuine sequences and not pseudogenes, contamination or chimeric sequences. A first set of extractions and sequencing was performed in 2008-2009 on a subset of the historical samples at the Molecular Laboratory of the Museum of Vertebrate Zoology, UC Berkeley. A second set of extractions and sequencing was performed in 20132014, on independent individuals, at the Molecular Laboratory of the Museum National d'Histoire Naturelle, Paris. In 2015, a subset of the samples extracted in 2007-2008 were reextracted at the Molecular Laboratory of the Museum National d'Histoire Naturelle, Paris and some fragments were re-sequenced; all sequences were identical to those obtained in 20072008 .

We sequenced one mitochondrial protein coding gene (ATP6), two autosomal introns (MB intron-2 and GAPDH intron-11) and one Z-linked intron (BRM intron-15). All primers used to PCR-amplify and sequence the modern and historical samples are detailed in Supplementary Table 2. The thermocycling conditions were standard and included a hotstart at $94^{\circ} \mathrm{C}$, an initial denaturation at $94^{\circ} \mathrm{C}$ for $3 \mathrm{~min}$, followed by $35-40$ cycles at $94^{\circ} \mathrm{C}$ for $40 \mathrm{~s}$, $52-60^{\circ} \mathrm{C}$ for $30 \mathrm{~s}$, and $72^{\circ} \mathrm{C}$ for $30-60 \mathrm{~s}$, completed by a final extension at $72^{\circ} \mathrm{C}$ for $5 \mathrm{~min}$. Purified PCR products were cycle-sequenced using the Big Dye terminator chemistry (ABI, Applied Biosystems) in both directions with the same primers used for PCR-amplification with the exception that primer G3P13 was replaced by G3PintL1 (Fjeldså et al. 2003), and were run on an automated ABI 3100 DNA sequencer. Heterozygous sites in nuclear loci were coded using the appropriate IUPAC code. Sequences newly generated for this study have 
been deposited in Genbank (www.ncbi.nlm.nih.gov; Accession Numbers XXXXX-XXXXX). All alignments are available from the first author upon request.

We used PHASE v2.1.1 (Stephens et al. 2001, Stephens and Donnelly 2003), as implemented in DNASP 5.0 (Librado and Rozas, 2009), to infer the alleles for each nuclear locus. Two runs were performed and the results were compared across runs. For sequences that were heterozygous in length, we compared the ambiguous 5'-end with the unambiguous 3 '-end of the forward and reverse sequences in order to resolve the placement and composition of gaps and the linkage of polymorphisms to those gaps (Peters et al. 2007).

\section{Phylogenetic analyses}

We used Bayesian inference (BI) as implemented and MRBAYES 3.2 (Ronquist et al. 2012) and maximum likelihood (ML), as implemented in RaxML 7.0.2 (Stamatikis 2006) to estimate phylogenetic relationships among the unique haplotypes/alleles. We used the nst $=$ mixed rates $=$ invgamma option for the gene tree analyses so that model selection uncertainty is taken into account in the analyses. Bayesian analyses for the two concatenated data sets (nuclear, nuclear and mitochondrial) were performed allowing the different parameters (base frequencies, rate matrix, shape parameter, transition/transversion ratio, proportion of invariable sites) to vary (using the prset ratepr=variable and unlink commands, i.e. mixed-models analyses following Nylander et al. 2004). For the concatenated analyses, the best-fitting partitioning strategy was selected using the Bayesian Information Criterion (BIC) and the greedy algorithm, as implemented in PARTITIONFINDER (Lanfear et al., 2012). Topologies were linked across partitions. Four to six Metropolis-coupled MCMC chains (one cold and three to five heated) were run for ten to twenty-five million iterations with trees sampled from the cold chain every 1000 iterations. We used default prior distributions for the substitution models and we tried several prior distributions for the estimation of branchlengths (exponential mean set to 10 - which is the default value, 50 or 100). The burn-in was set to $10 \%$ of the total iterations (i.e. between 1 and $2.5 * 10^{6}$, depending on the number of total iterations). Two independent Bayesian runs initiated from random starting trees were performed for each data set, and the log-likelihood values were compared within and among runs to ensure that the algorithm was not trapped at a local optimum. We checked that the potential scale reduction factor (PSRF) approached 1.0 for all parameters and the average standard deviation of split frequencies was less than 0.01. We used TRACER v1.6 (Rambaut et al. 2014) to check that our effective sample size of the underlying posterior distribution was 
large enough (> 200) for a meaningful estimation of parameters. For the ML analyses we used the GTRGAMMA model for all loci and assessed nodal support through 1000 bootstrap replicates. We performed mixed models analyses for the concatenated analyses (-q option). Analyses were run on the Cipress 3.1 gateway (Miller et al. 2010) or on T-Rex (Boc et al. 2012).

\section{Species-tree analyses}

Species trees were reconstructed using the coalescent-based model (*BEAST, Heled and Drummond 2010), implemented in BEAST v.1.8 (Drummond et al. 2002, 2006, 2012) on the Cipress 3.1 gateway (Miller et al. 2010). The species tree analyses were conducted without two taxa: Campethera mombassica, for which we could not obtain any data for the Z-linked locus and Dendropicos abyssinicus, for which no nuclear sequences could be obtained. To reduce parameter space, we did not partition the mitochondrial locus; models used for the species tree analyses were GTR + G for ATP6, GTR + G with equal base frequencies for MB, and $\mathrm{HKY}+\mathrm{G}$ for BRM and GAPDH. We performed the analyses in a relative time framework and specified 10 time units (normal distribution, mean $=10.0$, standard deviation $=0.05)$ for the first split within the Picinae. We specified a strict molecular clock for all loci and used uniform prior with ranges $0-0.5$ substitution per site per lineage and 0-0.1 substitution per site per lineage for the mitochondrial and nuclear loci, respectively. Two runs were conducted for $250 * 10^{6}$ iterations, with trees and parameters sampled every 2500 iterations. The first $25^{*} 10^{6}$ iterations were discarded as the burnin period. We used TRACER v1.6 (Rambaut \& Drummond 2007) to ensure that our effective sample size for all Bayesian analyses of the underlying posterior distribution was large enough (>200) for meaningful estimation of parameters.

\section{Divergence time analyses}

We used BEAST v1.8 (Drummond et al. 2002, 2006, 2012) to generate a chronogram. We applied the same partitioning strategy and models as in the concatenated analyses, and we specified an independent uncorrelated lognormal clock model for each partition (Drummond et al. 2006). To avoid any dependency of our results on the assignment of a particular fossil to a clade or on the use of a substitution rate that does not apply to the Picidae, we performed the divergence times analyses in a relative time framework and specified 10 time units (normal distribution, mean $=10.0$, standard deviation $=0.05$ ) for the first split within the Picinae. We assumed a birth-death process for the tree prior, uncorrelated lognormal molecular clock 
model with uniform prior distributions for the ucld.mean parameter and used default prior distributions for all other parameters, ran two analyses with MCMC chains for 25 million generations.

\section{Biogeography}

We used the likelihood-based method implemented in BIOGEOBEARS (BioGeography with Bayesian (and likelihood) Evolutionary Analysis in R Scripts (Matzke, 2014) to investigate the biogeographic history of the African woodpeckers. We compared the Dispersal-Extinction-Cladogenesis (DEC) model of LAGRANGE (Ree et al. 2005, Ree and Smith, 2008) to the DEC $+\mathrm{j}$ model of Matzke (2014). The latter model differs by the addition of a founder event speciation parameter, $j$. The best likelihood model (DEC versus DEC $+j$ ) was selected using a Likelihood Ratio Test.

Based on the results from Linder et al. (2012), we specified six areas for the analyses: Somalian (including Ethiopian), Sudanian, Zambezian, South African, Guinean and Congolian. Our designated areas are slightly different from the ones used by Linder et al. (2012) in that Linder et al. (2012) recognized the Guinean and Congolian regions as similar and the Somalian and Ethiopian as distinct. This decision was made in recognition that several woodpecker species are endemic to the Guinean area. The Ethiopian and Somalian areas were consider similar because; 1) all taxa distributed in the Somalian area are also distributed in the Ethiopian area, and 2) the Somalian area does not have any endemic species.

For all analyses, we used the maximum clade credibility tree from the BEAST concatenated analyses and assumed a symmetric one-rate model. Analyses were performed independently on the two African woodpecker assemblages. We only included one individual per species for the BIOGEOBEARS analyses and performed the analyses using two schemes concerning the number of recognized species (BGMYC and 'Phylogenetic', see below).

\section{Statistical tests for species delimitation and diversification rates}

Estimation of the respective rate of diversification through time for the genera Campethera/Geocolaptes and Dendropicos was obtained using the APE (Paradis et al. 2004), LASER (Rabosky 2006a, b), BAMM (Rabosky 2014) and BAMMTOOLS (Rabosky et al. 2014) packages, as implemented in R2.15 and R3.01 (http://www.r-project.org/; R Core Team, 2013). All taxa that did not cluster within the Campethera and Dendropicos clades were 
pruned from the chronogram. We performed the diversification rates analyses independently for the two African woodpecker assemblages. We attempted to make our sampling exhaustive at the species level. The number of species within a clade is a crucial parameter for the downstream diversification rate analyses. We tested the impact of the taxonomic decisions by using two strategies to select the lineages that may be considered species. First, we used a Bayesian implementation of the general mixed Yule-coalescent model (BGMYC 1.0; Reid and Carstens 2012) on the concatenated gene trees. This implementation is an extension of the GMYC model (Pons et al. 2006) that incorporates gene tree uncertainty by sampling over the posterior distribution of the trees. We used 100 trees randomly sampled from the posterior distribution of the mitochondrial divergence time analyses. Our second strategy involved selecting lineages that may deserve species status based on a combination of traditional hypotheses (e.g. species status for Campethera mombassica) and those lineages that represent deeply divergent monophyletic clades relative to traditionally recognized species pairs in our topology.

The BAMM (Rabosky 2014) and BAMMTOOLS (Rabosky et al. 2014) analyses were run under the 'speciationextincton' model, assuming a sampling probability of one (that is assuming all species were sampled) and defaults priors. The MCMC simulations were ran for $25^{*} 10^{6}$ iterations, using four chains, with samples recorded every 1000 iterations.

We estimated the empirical gamma statistic (Pybus and Harvey 2000) on the maximum clade credibility (MCC) tree and 1000 random trees from the posterior distribution obtained from the BEAST v1.8 analyses using the GamStat command. We tested for temporal variation in diversification rates using the $\triangle \mathrm{AICrc}$ statistic. This test represents the difference in AIC scores between the best rate-constant and rate-variable models. Because selecting the model with the lowest AIC criterion results in a high Type I error rate (Rabosky 2006a), we generated 1000 phylogenies under the purebirth model using the YuleSim function. For the latter simulations, we used the empirical speciation rate for each data set. We then compared the percentage of $\triangle \mathrm{AICrc}$ values that were greater than our observed value. If $5 \%$ of the simulated values were greater than our observed value, we considered the hypothesis of constancy in diversification rates not to be?/to not be rejected.

We did not perform any simulations to assess the impact of unsampled species on the output of the diversification rates analyses; we sampled all currently recognized species as well as all taxa that are considered by some taxonomists to be valid species. 


\section{RESULTS}

\section{Phylogenetic relationships}

\section{Mitochondrial data}

We did not detect any internal stop codon or double peaks in the electropherograms, suggesting that we did not amplify pseudogenes. We obtained mitochondrial DNA sequence data for the 126 sampled individuals, representing 110 haplotypes. The log-likelihood values of the two independent Bayesian runs were very similar and in both analyses the potential scale reduction factor (PSRF) approached 1.0 for all parameters and the average standard deviation of split frequencies was less than 0.01. The effective sample size of the underlying posterior distribution for each parameter was large enough (> 200) for a meaningful estimation. Neither the genus Campethera nor the Dendropicos clade were recovered as monophyletic (Supplementary Figure 1). Geocolaptes was nested within Campethera (PP: 0.95; B: 60\%) and sister to the clade formed by all Campethera species with the exception of $C$. caroli and $C$. nivosa that are sister to each other and form the basal lineage of the Campethera/Geocolaptes assemblage (PP: 1.0; B: 97\%). Although the genus Chloropicus $(C$. namaquus, C. pyrrhogaster, C. xantholophus) (PP: 0.99; B: 62\%) was more closely related to the Indo-Malayan D. mahrattensis than to other members of the Dendropicos clade, this node was not supported (PP: 0.60; B: 60\%). The remaining species from the Dendropicos clade grouped together (PP: 1.0; B: 73\%). Within the latter clade, the two polytypic genera (Dendropicos and Mesopicos) were not monophyletic. Mesopicos elliotii was nested within a clade that includes all but one Dendropicos species (PP: 1.0; B: 77\%) whereas D. stierlingi grouped with the monotypic Ipophilus obsoletus and the remaining Mesopicos taxa (PP: 1.0; B: $84 \%)$.

In the Campethera clade, one of the superspecies is not monophyletic, the Nubian Woodpecker $C$. nubica is only distantly related to $C$. punctuligera, $C$. bennettii and $C$. scriptoricauda. The remaining species from the $C$. punctuligera superspecies form a grade (PP: 1.0; B: 80\%), with $C$. punctuligera being the sister to the $C$. abingoni superspecies complex (C. abingoni, C. mombassica, C. notata; PP: 0.98; B: 65\%). The affinities of $C$. tullbergi (PP: 1.0; B: 90\%) were unresolved but considerable genetic divergence (6.6\%) was recovered between the two allopatric subspecies, C. t. tullbergi (SW Cameroon and Nigeria) and C. t. taeniolaema (East Africa). 


\section{Nuclear data}

For each individual locus, and the concatenated nuclear data set the log-likelihood values of the two independent Bayesian runs were very similar and in both analyses the potential scale reduction factor (PSRF) approached 1.0 for all parameters and the average standard deviation of split frequencies was less than 0.01 . The effective sample size of the underlying posterior distribution for each parameter was large enough (> 200) for a meaningful estimation.

\section{Autosomal data}

The analyses were performed on the unique alleles for MB (705 bp, 122 individuals, 169 unique alleles). The results indicate that alleles are widely shared among subspecies from the same species (e.g in M. griseocephalus or D. fuscescens) and are also sometimes shared between closely related species (e.g. M. griseocephalus/D. stierlingi). In several cases, alleles from a species did not form a monophyletic group (e.g. M. griseocephalus, C. punctuligera). Within the Campethera clade (PP: 1.0; B: 80\%), three primary lineages more or less well supported emerged: 1) C. caroli/C. nivosa (PP: 0.62; B: 61\%); 2) Geocolaptes (PP: 1.0; B: $100 \%$ ); and 3) the remaining Campethera species clustered together (PP: 0.93; P: 61\%). No support was recovered for any interspecific relationships. All the species from the Dendropicos clade clustered together but relationships in this clade were largely unresolved (Supplementary Figure 2).

The analyses performed on the unique alleles for GAPDH (457 bp, 116 individuals, 119 alleles) indicated that alleles were widely shared among subspecies and even in a few cases among species (C. caroli and C. nivosa, D. gabonensis and D. lugubris, D. leucotos and P. mixtus). With the exception of a few cases (e.g. C. nubica, D. fuscescens, M. griseocephalus), alleles from a species clustered together. Few relationships were supported with the Campethera and Dendropicos clades (Supplementary Figure 3).

\section{Z-linked locus}

The final alignment for BRM was 390 bp (116 individuals, 76 unique alleles). We could not obtain any sequence for three taxa: C. mombassica, D. abyssinicus, and $M$. spodocephalus spodocephalus. In several cases, alleles were shared among species (e.g. D. poecilolaemus and D. fuscescens; C. abingoni and C. notate; C. c. permista and C. maculosa; 
D. minor, D. leucotos and D. major). The genera Campethera and Geocolaptes clustered together (PP: 0.99; B: 53\%) but with the exception of the clade formed by $C$. caroli and $C$. nivosa (PP: 1.0; B: 77\%) no relationships among species were strongly supported. The species from the Dendropicos clade grouped with D. mahrattensis and D. medius in a clade (PP: 1.0; B: $65 \%$ ) in which most of the relationships are unresolved if we except the strong support for the monophyly of Chloropicus (PP: 1.0; B: 96\%) and the monophyly of the D. goertae superspecies (PP: 0.98; B: 60\%) (Supplementary Figure 4).

\section{Nuclear concatenated and species tree}

For the concatenated nuclear data set the log-likelihood values of the two independent Bayesian runs were very similar and all convergence estimators (PSRF, average standard deviation of split frequencies) had satisfactory values. The effective sample size of the posterior distribution for each parameter was > 200). For the species tree analyses, most of the parameters had effective sample size in the individual runs greater than 100 after running 250 million iterations, with the exception of the speciation likelihood, for which the effective sample size was 80-100 in the individual runs. Combining the two runs improved the effective sample size of the posterior distributions and all parameters but the speciation likelihood had effective sample size greater than 200 .

The topology recovered from the concatenated analyses of the three nuclear loci (123 individuals, 1573 bp; Supplementary Figure 5) recovered the monophyly of the Campethera (PP: 1.0; B: 100\%) and Dendropicos clades (PP: 1.0; B: 84\%). Several species (e.g. C. bennettii, $M$ griseocephalus, D. fuscescens) from the Campethera and Dendropicos clades were paraphyletic or polyphyletic in the concatenated topology. Within the Campethera clade, three primary lineages emerged: 1) the C. caroli/C. nivosa clade (PP: 1.0; B: 100\%); 2) Geocolaptes (PP: 1.0; B: 100\%); and 3) the remaining Campethera species (PP: 0.99; B: 69\%). Within the latter clade, the 'abingoni' (PP: 1.0; B: 96\%) and 'cailliautii' (PP: 1.0; B: 100\%) superspecies were both recovered as monophyletic. The 'nubica' superspecies was polyphyletic as $C$. bennettii was more closely related to the 'abingoni' superspecies (PP: 0.95; B: $44 \%$ ) than to the C. nubicalC. punctuligera clade (PP: 0.98; B: 62\%). The relationships of C. tullbergi were unresolved. For the Dendropicos clade, the genus Chloropicus (PP: 1.0; B: 94\%) was found to be the first diverging (PP: 0.97; B: 69\%). Two clades emerged among the remaining members of the Dendropicos clade. The first clade consisted of all species from the genus Mesopicos with the exception of M. elliotii (PP: 1.0; B: 80\%). The second clade 
included all species from the genus Dendropicos, I. obsoletus and M. elliotii (PP: 0.99; B: 49\%). With the exception of $D$. elachus being recovered as sister to $D$. fuscescens/D. poecilolaemus clade (PP: 0.98; B: 64\%) very few associations among species were supported. The species tree analyses of the nuclear loci recovered topologies that were very similar to the concatenated nuclear analyses (Figure 3A), although support values were generally lower (e.g. monophyly of the Dendropicos clade; PP: 0.84 versus PP: 1.0 and B: $84 \%$ in the concatenated analyses). The concatenated and species tree analyses mostly differ in two nodes. The first involves $C$. nubica that is sister to $C$. punctuligera ssp in the concatenated analyses (PP: 0.98; B: 62\%) and sister to C. bennetii ssp/C. scriptoricauda in the species tree analyses (PP: 0.41). The second difference involves the relationships of I. obsoletus, D. stierlingi and D. gabonensis ssp which were related to the Dendropicos sensu stricto clade in the concatenated analyses (PP: 0.99; B: 48\%) or to the M. goertae ssp/M. griseocephalus clade in the species tree analyses (PP: 0.49)

\section{Mitochondrial and nuclear: concatenated and species tree analyses}

For the concatenated mitochondrial and nuclear data set the log-likelihood values of the two independent Bayesian runs were very similar and all convergence estimators (PSRF, average standard deviation of split frequencies) had satisfactory values. The effective sample size of the posterior distribution for each parameter was $>200$ ). For the species tree analyses, most of the parameters had effective sample size in the individual runs greater than 100 after running 250 million iterations, with the exception of the speciation likelihood, for which the effective sample size was 46 in the individual runs. Combining the two runs did barely improve the effective sample size of the posterior distributions; all parameters but the speciation likelihood had effective sample size greater than 100 .

The tree obtained using the concatenated data set (126 individuals, $2260 \mathrm{bp}$; Figure 2) was well resolved overall. Neither the genus Campethera nor the genus Dendropicos were recovered as monophyletic since Geocolaptes and Dendrocopos obsoletus were nested within Campethera and Dendropicos, respectively. The monophyly of the Campethera clade was well supported (PP: 1.0; B: 100\%) as was the basal position of the C. caroli/C. nivosa clade (PP: 0.99; B: 100\%). The Ground Woodpecker (Geocolaptes) was sister to all remaining Campethera species (PP: 1.0; B: 91\%). The monophyly of the C. abingoni (C. abingoni, $C$. mombassica, C. notata; PP: 1.0; B: 100\%) and C. caillautii (C. cailliautii, C. maculosa; PP: 1.0; B: 100\%) superspecies were strongly supported. The monophyly of the third superspecies 
(C. punctuligera, C. nubica, C. bennettii/C. b. scriptoricauda) was not confirmed. The Bennett's (C. b. bennettii/b. capricorni)/Reichenow's (C. b. scriptoricauda) Woodpeckers clade (PP: 1.0; B: 100\%) was sister to the C. abingoni species complex (PP: 0.96; B: 71\%); whereas the phylogenetic placement of C. punctuligera and $C$. nubica could not be determined with confidence in our topology. Finally, the phylogenetic position of $C$. tullbergii could not be resolved; substantial genetic divergence was found between the two subspecies (C. $t$. tullbergi and C. t. taeniolaema). The basal lineage branching off the backbone of the Dendropicos clade (PP: 0.97; B: 79\%) consists of the three species of the genus Chloropicus (PP: $1.0 ;$ B: $100 \%)$. The Fire-bellied (C. pyrrhogaster) and Golden-crowned $(C$. xantholophus) Woodpeckers were recovered as sister-species, although this relationship was not strongly supported. The remaining members of the Dendropicos clade were divided into two primary clades. The first clade (PP: 1.0; B: 67\%) includes I. obsoletus, D. stierlingi together with three species from genus Mesopicos (PP: 1.0; B: 100\%). The African Grey Woodpecker (D. goertae) was the first species to diverge and the Olive (D. griseocephalus) and Eastern Grey (D. spodocephalus) Woodpeckers were recovered as sister species. The second clade consists of the seven remaining species (PP: 1.0; B: 84\%), with the Abyssinian Woodpecker ( $D$. abyssinicus) the first species to split off, followed sequentially by the $D$. gabonensis superspecies (D. gabonensis-D. lugubris), Elliot's Woodpecker (M. elliotii) and the D. fuscescens superspcies complexes (D. elachus/D. poecilolaemus/D. fuscescens; PP: 1.0; B: 100\%). Within the latter superspecies, the Speckle-breasted (D. poecilolaemus) and Cardinal (D. fuscescens) Woodpeckers were recovered as sister-species (PP: 1.0; B: 96\%).

The species tree analyses recovered topologies that were very similar to the concatenated analyses (Figure 3B); the topological differences between the two classes of methods only implied relationships among proximate outgroups or nodes in polytomy in one of the two methods (e.g. C. nubica). Although the relationships among taxa were identical, the support values in the species tree analyses were lower than in the concatenated analyses (e.g monophyly of Campethera/Geocolaptes: BI Concatenated/Species tree: 1.0/ 0.91, monophyly of Dendropicos s.1.: BI Concatenated/Species tree: 1.0/0.45)

\section{Divergence time analyses}

The effective sample size of the posterior distribution for each parameter was above 200 for all parameters excepted one (ATP6 base frequencies for A), for which the effective 
sampled size was 185 . The divergence time analyses suggested that the Campethera and Dendropicos clades split from their Indo-Malayan relatives at slightly different times (Campethera clade: 6.1 TU, 95\% HPD 5.0-7.4; Dendropicos clade: 4.6 TU 95\% HPD: 3.85.5; Supplementary Figure 6) but started to diversify at the same time (Campethera clade: 4.4 TU, 95\% HPD 3.5-5.4; Dendropicos clade: 4.3 TU 95\% HPD: 3.5-5.1). Divergence times among some well recognized biogeographic realms point either toward a single event (e.g. origin of the Sudanian endemics: C. punctuligera 2.5 TU 95\% HPD: 2.0-3.2; M. goertae 2.0 TU 95\% HPD: 1.5-2.6; I. obsoletus 2.4 TU 95\% HPD: 1.7-3.1; Ethiopian/Somalian subregion endemics: D. abyssinicus 3.1 TU 95\% HPD: 2.4-3.8 C. nubica 2.9 TU 95\% HPD: 2.2-3.6) or to multiple divergence events (e.g. Upper versus Lower Guinea Forest blocks: C. maculosa 0.5 TU 95\% HPD: 0.3-0.7, D. lugubris 1.4 TU 95\% HPD: 0.9-2.0). Finally, the two South African endemics also have different origins in time; Geocolaptes diverged from its sistergroup about 3.9 TU ago (95\% HPD: 3.1-4.8) whereas $C$. notata diverged from the $C$. abingoni/C. mombassica clade about 1.2 TU ago (95\% HPD: 0.8-1.7).

\section{Statistical tests for species delimitation}

The results from the BGMYC analyses indicate that several lineages within the Campethera and Dendropicos clades may warrant recognition as full species (Supplementary Figure 7). In most cases, the lineages that were recognized as distinct by the BGMYC algorithm represent taxa for which the taxonomic status is already in a state of flux (e.g. Campethera t. tullbergii and C. t. taeniolaema). The results from the BGMYC analyses suggest the need to recognize 13 species instead of 12 (Dickinson and Remsen Jr 2013) within the Campethera clade: C. n. herberti, C. t. taeniolaema C. b. scriptoricauda should be elevated to species, but $C$. maculosa and $C$. mombassica should be lumped with $C$. cailliautii and $C$. abingoni respectively. For the Dendropicos clade, the BGMYC analyses suggest the need to recognize two further species, Mesopicos spodocephalus and Dendropicos lugubris. Hence, the species level diversity has been underestimated in both the Campethera and Dendropicos clades but that species limits have been more difficult to draw in the Campethera clade than in the Dendropicos clade given the need to both split and lump taxa. We make further use of the results from the BGMYC analyses to inform for the biogeographic and diversification rates analyses by implementing two schemes (Table 1): 1) BGMYC results, and 2) under a phylogenetic species concept where herein all lineages are recognized as putative species if the genetic divergence from their sister-lineage exceeds the 
genetic divergence of the most recently diverged species pair in the clade, and where there are concomitant morphological differences.

\section{Biogeographic analyses}

The DEC $+\mathrm{j}$ model was favoured over the DEC model in all four comparisons that were made (LRT, chi-square range $=6.64-15.82, \mathrm{p}$ value range $=0.01$ to $<0.001$; Table 2 , , suggesting that a model assuming founder speciation events had a better fit to the data. Hence, we present only the results with the $+\mathrm{j}$ parameter.

For the Campethera clade, the biogeographic analyses performed using BIOGEOBEARS and the DEC $+\mathrm{j}$ model suggest the most likely ancestral range for the Geocolaptes/Campethera clade comprises multiple, almost as likely, combinations of ancestral ranges and are apparent at the root of Campethera (Figure 4). A noticeable feature of that topology is that most of the initial splits (Geocolaptes being the exception) involved species that are restricted to the Guinean and Congolian forests blocks (C. caroli, C. nivosa, C. maculosa, C. permista, C. taeniolaema, C. tullbergii); this suggests that the earliest speciation events mostly involved habitat specialisation between dense forest (GuineoCongolian realms) versus woodland/open forest (Zambezian, Sudanian, Southern African and Somalian) whereas the later speciation events occurred among allopatric/parapatric taxa distributed across similar habitat types (savannah belt for the Southern African, Sudanian, Zambezian and Somalian realms; clade C. abingoni/C. nubica clade).

For the Dendropicos clade, the biogeographic analyses performed using BioGeoBEARs and the DEC $+\mathrm{j}$ model suggests that the most likely ancestral range for the Dendropicos clade either consists of all areas or that it is unresolved. (Figure 4) Most of the first splits involve the species found in the Guinean and Congolian Forest blocks $(C$. xantholophus, C. pyrrhogaster, D. lugubris, D. gabonensis, M. e. elliotii, M. e. johnstoni), suggesting that the earliest speciation events mostly involved habitat specialisation between dense forest (Guineo-Congolian realms) versus woodland/open forest (Zambezian, Sudanian, Southern African and Somalian), a situation similar to that encountered in Campethera/Geocolaptes. Later speciation events mostly involved allopatric/parapatric taxa occurring in similar habitat types. Yet, the number of speciation events implicating habitat specialisation (Guinean and Congolian realms for dense forest versus Zambezian, Sudanian, 
Southern African and Somalian for savannah/woodland) among members of the Dendropicos clade is greater than for the Campethera clade.

\section{Diversification rates analyses}

The numbers of species retained for the diversification rates analyses varied between 13 and 18 (Campethera; BGMYC and 'Phylogenetic' taxa sets, respectively) and 15 and 19 (Dendropicos; BGMYC and 'Phylogenetic' taxa sets, respectively) (Table 1).

The $\gamma$ statistic (gamStat function) on the maximum clade credibility tree was significantly negative for both the Campethera $(\gamma=-2.473, \mathrm{p}=0.007)$ and Dendropicos clades $(\gamma=-3.11, \mathrm{p}<0.001)$ using the 13 and 15 species hypotheses, respectively. This is indicative of a decrease in diversification rate over time. Using 18 and 19 species for Campethera and Dendropicos, respectively, resulted in a statistically significant decrease in diversification rate being only recovered for the Dendropicos clade $(\gamma=-2.454, p=0.007$; Campethera clade $\gamma=-1.283, \mathrm{p}=0.10)$. Under an exhaustive sampling scheme, the critical $\gamma$ must be smaller than -1.645 to detect a decrease in diversification rate. The posterior distributions of the $\gamma$ statistic (1000 random trees) confirm the results based on the MCC tree (Figure 5).

We did not find any discrete change in diversification rate in the Campethera or Dendropicos clades using the algorithm implemented in BAMM (Figure 5). Instead, there was evidence for a decrease in diversification rate that appeared to be gradual for each woodpecker clade. We explicitly tested this hypothesis using the $\triangle \mathrm{AICrc}$ statistic implemented in LASER. Models that assume variation in diversification rate through time were always favoured for both the Campethera and Dendropicos clades, irrespective of the assumption concerning the number of recognized species (Density Dependent Logistic over Purebirth; smallest $\Delta \mathrm{AICrc}=1.016998$, Campethera, 18 species). These conclusions remained robust after simulations (Table 3 , highest $\mathrm{p}$-value $=0.016$ ) with the exception of the case where the number of Campethera species was 18, where a Purebirth model could not be rejected $(\mathrm{p}=0.16)$.

Hence, we cannot statistically reject a model of constant diversification for the Campethera clade. In contrast, our analyses suggest a linear decrease in diversification rate was favoured for the Dendropicos clade even with the recognition of a greater number of 
species (Figure 5). These results suggest that while the two clades may have slightly different diversification dynamics, these differences are driven by how many species are recognized in each clade.

\section{DISCUSSION}

It has previously been suggested that woodpeckers colonized Africa twice from IndoMalaya (Fuchs et al. 2007, 2013), but further insights into the evolution of African lineages was not previously possible due to limitations in sampling. Our study provides the first molecular assessment of the systematic relationships and biogeographic history of the endemic African assemblages of woodpeckers. Using a combination of nuclear and mitochondrial DNA sequence data, our analyses indicate that Geocolaptes is nested within Campethera as presently defined, and confirm that Ipophilus obsoletus is part of the Dendropicos clade (Fuchs and Pons 2015, Dufort 2016). Our analyses also reveal that the two lineages possibly have slightly different diversification dynamics, despite having colonized Africa from Indo-Malayan ancestors at about the same time. While a decrease in diversification rate is most likely explained by a diversity-dependent model for the Dendropicos clade in all analyses, a constant diversification rate or a diversity-dependent model is selected for the Campethera clade depending on the number of species included in the analyses.

\section{Phylogeny and taxonomy}

Our analyses clarified several disputed species relationships pertaining to the systematics of African woodpeckers. We propose taxonomic changes at both the genus and species levels. We suggest that the species $C$. caroli and C. nivosa be placed in the resurrected genus Stictopicus Malherbe, 1861. This scheme would retain the monotypic genus Geocolaptes for the Ground Woodpecker (G. olivaceus), which we consider taxonomically useful, as this species is highly divergent in morphology from the remaining species in the now more restrictive genus Campethera. The alternative would be to recognize a single genus (Geocolaptes by priority) for all species traditionally attributed to Campethera and Geocolaptes. The genus name Geocolaptes was originally used to describe an atypical species (terrestrial, larger size, longer bill) primarily restricted to the Fynbos bioregion (South Africa), with respect to other Campethera species; retaining all African species into a genus that was 
initially named for an atypical species would weaken the power of classification by misleadingly implying that the species are entirely or mostly terrestrial (use of adverb Geo-).

Recent classification efforts (e.g. Dickinson and Remsen Jr 2013) have proposed four genera for members of the Dendropicos clade. Our phylogenetic analyses suggest that two of these genera, Mesopicos and Dendropicos, are not monophyletic as presently defined, and that Ipophilus is nested within Mesopicos. Several schemes are possible to render the taxonomy consistent with the phylogeny. One approach would be to lump all species into a single genus, Dendropicos, as traditionally adopted by several authors. Another would be to recognize two (Chloropicus, Dendropicos) or three (Chloropicus, Dendropicos, Mesopicos) genera, corresponding to the three primary clades. The recognition of more than one genus would more accurately reflect that Chloropicus species are relatively divergent from other members of the Dendropicos clade. Further, recognizing two or three genera would also be consistent with the number of genera recognized for the Campethera clade (see earlier discussion), which is made up of a similar number of species and has similar diversification dynamics. We here propose a new classification for African woodpeckers that takes into account the relationships recovered in our analyses.

For the species level, our reasoning about whether to split or merge taxa is based on a combination of monophyly (but see Funk and Omland 2003 about the importance of this criterion for defining a species), morphology, level of geographic and subspecies sampling, and genetic distance between the sister-species pair relative to other congeners. At the species level we propose to recognize the species status of six taxa that have allopatric or parapatric distributions (C. c. arizela from C. c. caroli, C. n. herberti from C. n. nivosa, C. $t$. taeniolaema from C. t. tullbergi, C. b. scriptoricauda from C. b. bennetti, D. g. lugubris from D. g. gabonensis, M. g. spodocephalus from M. g. goertae). The taxonomic status of $C$. permista (lowland forest) and C. cailliautii (wooded savannah) is more difficult to assess as the two taxa have different plumage characteristics but possess limited genetic distances, continuous distribution, and hybridize in Angola and the DR Congo (Fry et al. 1988), Altogether, our data would suggest that two taxa are part of the same biological species but we also highlight that small genetic distances are not always reliable indicators of species divergence. Cleary, further sampling is needed to estimate the extant of gene flow and differentiation across the habitat boundaries throughout the distribution of these two taxa. Further genetic studies with more thorough geographic sampling are also clearly needed to 
fully resolve the taxonomic boundaries among populations of three woodpecker species with large continuous distributions and where our sampling recovered substantial genetic differentiation among localities: C. punctuligera, D. fuscescens and I. obsoletus.

\section{Biogeography}

Our analyses indicate that both lineages started to diversify at the same time (Campethera clade: 4.4 TU, Dendropicos clade $4.3 \mathrm{TU}$ ) despite having diverged from their closest Indo-Malayan relatives at slightly different times (Campethera clade: $6.1 \mathrm{TU}$; Dendropicos clade: 4.6 TU). In both clades, biogeographic reconstructions indicate that the Guineo-Congolian forest block was the most likely ancestral area, although competing combinations were almost equally likely, suggesting that tropical forest was the ancestral habitat of both clades. This pattern is similar to the pattern recovered by Voelker et al. (2016) for muscicapid flycatchers, where their analyses recovered the Guineo-Congolian realm as the ancestral area for the African assemblage. The colonization of more open habitats (e.g. Sudanian endemics or nearly so) appears to have occurred during a single time period $(C$. punctuligera 2.5 TU; M. goertae 2.0 TU, D. elachus 2.0 TU, I. obsoletus 2.4 TU). According to our analyses most of the more open habitat lineages diversified during the 2-3 TU bp period. Yet, concluding that a single event in earth history explains the origin of most species endemic to a single bioregion would be a gross oversimplification. Indeed, the timing of origin for some species in the Guineo-Congolian forest block appears to differ significantly (e.g. C. maculosa/C. cailliautii 0.5 TU 95\% HPD: 0.3-0.7, D. lugubris-D. gabonensis 1.4 TU 95\% HPD: 0.9-2.0). Collectively, these results suggest the occurrence of repeated cycles of allopatric isolation within these biogeographic realms as having been an important process in driving lineage diversification of African woodpeckers. Based on our results for woodpeckers and the very few studies that have investigated phylogeographic structure of GuineoCongolian endemic birds (e.g. Marks 2010, Fuchs and Bowie 2015, Huntley and Voelker 2016), an emerging trend across these studies is the importance of repeated cycles of forest expansion and contraction that resulted in lineage divergence during allopatry (Fjeldså and Bowie 2008, Voelker et al. 2010).

\section{Diversification dynamics in the two genera}

Our diversification rate analyses reveal that despite having a comparable number of species and being of the same age, the two lineages have slightly different diversification 
dynamics. Diversification rates in Campethera appear to have decreased or remained constant over time depending on how we taxonomically consider $C$. $c$. permista, whereas speciation rates in Dendropicos are decreasing through time in a density-dependent fashion whereby diversification rate decreases as the number of lineages increases (Nee et al. 1992). One of the biological mechanisms that may result in density-dependent diversification implies ecological limitations to species diversity; higher speciation rates occur at the early stage of colonization when a linage colonizes an area in which a resource is under- or unexploited. Diversification may then slow down as competition increases from congeners (Hardy and Cook 2012). This result might at first seem surprising given the similarity in overall shape and behaviour among woodpeckers. Yet species from the Dendropicos clade are typically more arboreal than members of the Campethera clade, possessing stronger claws and a less curved bill than most members of the genus Campethera (Winkler and Christie 2002). These morphological attributes reach their maximum in Geocolaptes, which inhabits open rocky outcrops with no trees in the Cape and Natal biogeographic regions. The genus Geocolaptes also represents a clear outlier for body mass (119.5 g) relative to other members of the Campethera clade $($ mean $=62.3 \mathrm{~g}$ SD 10.8, range 39.5-112.5, $\mathrm{n}=12$ species ; without Geocolaptes mean $=56.6 \mathrm{~g}$ SD 6.5, range 39.5-72.5, $\mathrm{n}=11$ species), whereas the genus Dendropicos is heterogeneous in body mass (mean 38.9 g SD 15.3, range 19-75, n = 13 species; Winkler and Christie 2002). The pattern observed for Dendropicos matches what is also observed at a larger scale within the mutually paraphyletic genera Dendrocopos, Picoides and Veniliornis, where species of comparable size belong to the same clade (e.g. Ouellet 1977, Weibel and Moore 2002a, b, Moore et al. 2006, Fuchs and Pons 2015). In the Western Palearctic or the Nearctic, two to three members of the Pied Woodpecker clade (Fuchs and Pons 2015) can coexist in the same habitat or forest patch; these species usually differ in body mass and forage on slightly different parts of the tree or use different cavity sizes for nesting (Winkler and Christie 2002). This pattern is also seen in Africa, where two species that diverge in body mass ( $D$. fuscescens and D. namaquus) can be seen in the same species flock (Hockey et al. 2005). Unlike Dendropicos species that are fully arboreal, species from the Campethera/Geocolaptes lineage are more varied in their feeding habits; some species (e.g. C. tullbergi, C. abingoni) are strictly arboreal, whereas other species are primarily terrestrial (e.g. C. scriptoricauda) or even restricted to treeless habitats (Geocolaptes). Hence, it is possible that Campethera reflects a pattern with no slowdown in diversification because some species (Geocolaptes, $C$. scriptoricauda) were able to continue to diversify in trait space to enable adaptation to a greater diversity of terrestrial habits, whereas members of the genus Dendropicos are adapted 
primarily to feed in trees. As the pattern for Campethera is dependent on the number of species we recognize, it is clear that phylogeographic studies on some species complexes are clearly needed to understand which diversification dynamics fits the best to this genus.

Classification

Genus Stictopicus Malherbe, 1861

Stictopicus caroli (Malherbe, 1851)

Stictopicus arizela (Oberholser, 1899)

Stictopicus nivosa (Swainson, 1837)

Stictopicus herberti (Alexander, 1908) (the relationships of the subspecies poensis Alexander, 1903 have not yet been assessed; if it is more closely related to herberti than to nivosa), the name for the species East of the Niger River should be poensis, Alexander, 1903; see Fuchs and Bowie 2015 for the phylogeographic pattern).

Genus Geocolaptes Swainson, 1832

Geocolaptes olivaceus (J. F. Gmelin, 1788)

Genus Campethera G. R. Gray, 1841

Campethera punctuligera (Wagler 1827) (includes balia (von Heuglin, 1871) until more detailed phylogeographic data is available)

Campethera bennettii (A. Smith, 1836)

Campethera scriptoricauda (Reichenow, 1896)

Campethera nubica (Boddaert, 1783)

Campethera abingoni (A. Smith, 1836)

Campethera mombassica (Fischer \& Reichenow, 1884) (we recognize this taxon as a species, although genetic divergence is very limited, until further sampling allows us to test for the occurrence of extant gene flow)

Campethera notata (M.H.C. Lichtenstein, 1823)

Campethera cailliautii (Malherbe, 1849) (including permista Reichenow, 1876 based on limited genetic divergence and reports of hybridization but phylogeographic studies are needed to estimate the extant of gene flow among taxa)

Campethera maculosa (Valenciennes, 1826)

Campethera tullbergi (Sjöstedt, 1892)

Campethera taeniolaema (Reichenow \& Neumann, 1895)

Genus Chloropicus Malherbe, 1845

Chloropicus namaquus (A.A.H. Lichtenstein, 1793)

Chloropicus xantholophus (Hargitt, 1883)

Chloropicus pyrrhogaster (Malherbe, 1845) 
Genus Dendropicos Malherbe, 1849

Dendropicos stierlingi Reichenow, 1901

Dendropicos goertae (Statius Muller, 1776)

Dendropicos spodocephalus (Bonaparte, 1850) (including rhodeogaster, Fischer \& Reichenow, 1884)

Dendropicos griseocephalus (Boddaert, 1783)

Dendropicos obsoletus (Wagler, 1829)

Dendropicos gabonensis (J. and E. Verreaux, 1818)

Dendropicos lugubris (Hartlaub, 1857)

Dendropicos abyssinicus (Stanley, 1814)

Dendropicos elliotii (Cassin, 1863)

Dendropicos elachus Oberholser, 1919

Dendropicos poecilolaemus Reichenow, 1893

Dendropicos fuscescens (Vieillot, 1818)

\section{ACKNOWLEDGMENTS}

We are grateful to P. Sweet, T. Trombone and J. Cracraft (AMNH), N. Rice (ANSP), D. Allan (DNSM), J. Bates, S. Hackett, T. Gnoske, B. Marks and D. Willard (FMNH), R. Moyle, M.B. Robbins and A.T. Peterson (KUMNH), R. Brumfield, D. Dittmann and F. Sheldon (LSU), C. Witt and A. Johnson (MSB), G. Boano and M. Pavi (MCCI), E. Pasquet and C. Denys (MNHN), P. Kaliba (Museums of Malawi), A. Johnsen, L.E. Johanssen and J. Lifjeld (NHMO), U. Johansson and P. Ericson (NRM), K. Njabo (UCLA), M. Melo (Fitzpatrick Institute, UCT), M. Braun and J. Dean (USNM), S. Birks and R. Faucett (UWBM), J. Fjeldså and J.-B. Kristensen (ZMUC), J. Heymans and K. Raijmakers for providing samples. We also thank: O. Davies, G. Dzikouk, P. Gaubert, A. Hassanin, D. de Swardt, P. Lloyd, F. Njiokou, G. Oatley, A. Ribeiro, A. Ropiquet, H. Smit, T. MandiwanaNeudani and G. Wogan for help in the field, and W. Matumba and J. van Wyk for access to Polokwane NR and Blouberg NR. Provincial authorities in the Eastern Cape (D. Balfour, B. Geach, Z. Gibisela, A. Southwood,) and Limpopo (J. Heymans, T. J. Seakamela) are thanked for granting permission to collect samples and specimens (permits 0112-CPM401-00001, CPM-002-00003, OP 3771/2009, CRO144/14CR). Specimens in Cameroon were collected under permits Nº920/PRBS/MINFOF/SG/DFAP/SDEV/SC, $\mathrm{N}^{\circ} 081 / \mathrm{MINRESI} / \mathrm{B} 00 / \mathrm{C} 00 / \mathrm{C} 10 / \mathrm{C} 11$, and CBCS/PDO/YFP/0017/12/12/07. Fieldwork in 
Malawi was conducted under permits issued to the Field Museum and Museums of Malawi. The Science Faculty Animal Ethics Committee of the University of Cape Town (clearance number: 2008/V26/JF), the IACUC committee of University of California at Berkeley (AUPR317) and Comite Cuvier (68-055 to JF) approved the handling and sampling of the individuals collected for this project. Help during laboratory work was kindly provided by C. Bonillo, D. Gey, J. Lambourdière and J. Utge (UMS2700, MNHN) and L. Smith (University of California, Berkeley). We are also very grateful to M. Balman and BirdLife International and NatureServe (2013) for providing the shape files used to make Figure 1. This work was supported by 'Service de Systématique Moléculaire' (UMS2700 Outils et Méthodes de la Systématique intégrative, MNHN), NSF grant DEB-1441652 to RCKB, and a postdoctoral fellowship to JF from the DST/NRF Centre of Excellence at the Percy FitzPatrick Institute. 


\section{REFERENCES}

Barker FK, Burns KJ, Klicka J, Lanyon SM, Lovette IJ, 2012. Going to extremes: contrasting rates of diversification in a recent radiation of new world passerine birds. Syst. Biol. 62: 298-320.

Becker RA, Wilks AR, 2013. mapdata: Extra Map Databases. R version by Brownrigg R. (2013) R package version 2.2-2. http://CRAN.R-project.org/package=mapdata

Benz BW, Robbins MR, Peterson AT, 2006. Evolutionary history of woodpeckers and allies Aves: Picidae): Placing key taxa on the phylogenetic tree. Mol. Phylogenet. Evol. 40: 389-399.

BirdLife International and NatureServe (2013) Bird species distribution maps of the world. BirdLife International, Cambridge, UK and NatureServe, Arlington, USA.Bivand R, Lewin-Koh N, 2014. maptools: Tools for reading and handling spatial objects. R package version 0.8-29. http://CRAN.R-project.org/package=maptools

Boc A, Diallo Alpha B, Makarenkov V, 2012. T-REX: a web server for inferring, validating and visualizing phylogenetic trees and networks. Nucleic Acids Res. 40: W573-W579.

Bowie RCK, Fjeldså J, Hackett SJ, Bates JM, Crowe TM, 2006. Coalescent models reveal the relative roles of ancestral polymorphism, vicariance and dispersal in shaping phylogeographical structure of an African montane forest robin. Mol. Phylogenet. Evol. 38: 171-188.

Bowie RCK, Fjeldså J, Hackett SJ, Crowe TM, 2004a. Systematics and biogeography of Double-Collared Sunbirds from the Eastern Arc Mountains, Tanzania. Auk 121: 660-681.

Bowie RCK, Fjeldså J, Hackett SJ, Crowe TM, 2004b. Molecular evolution in space and though time: mtDNA phylogeography of the Olive Sunbird (Nectarinia olivacea/obscura) throughout continental Africa. Mol. Phylogenet. Evol. 33: 56-76.

Dickinson EC, Remsen Jr JV (Eds) 2013. The Howard and Moore complete checklist of the birds of the world, fourth edition, vol 1, Aves Press, Eastbourne, UK.

Drummond AJ, Ho SYW, Phillips MJ, Rambaut A, 2006. Relaxed phylogenetics and dating with confidence. PLoS Biology 4: e88. 
Drummond AJ, Nicholls GK, Rodrigo AG, Solomon W, 2002. Estimating mutation parameters, population history and genealogy simultaneously from temporally spaced sequence data. Genetics 161: 1307-1320.

Drummond AJ, Suchard MA, Xie D, Rambaut A, 2012. Bayesian phylogenetics with BEAUti and the BEAST 1.7. Mol. Biol. Evol. 29: 1969-1973.

Fjeldså J, Bowie RCK, 2008. New perspective on the origin and diversification of Africa's forest avifauna. Afr. J. Ecol. 46: 235-247.

Fry CH, Keith S, Urban EK, 1988. The birds of Africa vol III. Academic Press, London.

Fuchs J, Bowie RCK, 2015. Concordant genetic structure in two species of woodpecker distributed across the primary West African biogeographic barriers. Mol. Phylogenet. Evol. 88: 64-74.

Fuchs J, Crowe TM, Bowie RCK, 2011a. Phylogeography of the Fiscal Shrike (Lanius collaris): A novel pattern of genetic structure across the arid zones and savannas of Africa. J. Biogeogr. 38: 2210-2222.

Fuchs J, Fjeldså J, Bowie RCK, 2011b. Diversification across an altitudinal gradient in the Tiny Greenbul (Phyllastrephus debilis) from the Eastern Arc Mountains of Africa. BMC Evol. Biol. 11: 117.

Fuchs J, Fjeldså J, Bowie RCK, in press. Diversification across major biogeographic breaks in the African Shining/Square-tailed Drongos complex (Passeriformes: Dicruridae). Zool. Scr.

Fuchs J, Ohlson JI, Ericson PGP, Pasquet E, 2006. Molecular phylogeny and biogeographic history of the piculets (Piciformes: Picumninae). J. Avian Biol. 37: 487-496.

Fuchs J, Ohlson JI, Ericson PGP, Pasquet E, 2007. Synchronous intercontinental splits between assemblages of woodpeckers suggested by molecular data. Zool. Scr. 36: 11-25.

Fuchs J, Pons J-M, 2015. A new classification of the Pied Woodpeckers assemblage (Dendropicini, Picidae) based on a comprehensive multi-locus phylogeny. Mol. Phylogenet. Evol. 88: 28-37.

Fuchs J, Pons J-M, Liu L, Ericson PGP, Couloux A, Pasquet E, 2013. A multi-locus phylogeny suggests an ancient hybridization event between Campephilus and melanerpine woodpeckers (Aves: Picidae). Mol. Phylogenet. Evol. 67: 578-588.

Fuchs J, Pons J-M, Ericson PGP, Bonillo C, Couloux A, Pasquet E, 2008. Molecular support for a rapid cladogenesis of the woodpecker clade Malarpicini, with further insights into the genus Picus (Piciformes: Picinae). Mol. Phylogenet. Evol. 48: 34-46. 
Funk DJ, Omland KE, 2003. Species-level paraphyly and polyphyly: frequency, causes, and consequences, with insights from animal mitochondrial DNA. Annu. Rev. Ecol. Evol. Syst. 34: 397-423.

Hardy NB, Cook LG, 2012. Testing for ecological limitation of diversification: a case study using parasitic plants. Am Nat 180: 438-449.

Hockey PAR, Dean WRJ, Ryan PG (eds), 2005. Roberts - Birds of Southern Africa, VIIth ed. The Trustees of the John Voelcker Bird Book Fund, Cape Town.

Huntley JW, Voelker G, 2016. Cryptic diversity in Afro-tropical lowland forests: The systematics and biogeography of the avian genus Bleda. Mol. Phylogenet. Evol. 99: 297308.

Lanfear R, Calcott B, Ho SYW, Guindon S, 2012. PartitionFinder: combined selection of partitioning schemes and substitution models for phylogenetic analyses. Mol. Biol. Evol. 29: $1695-1701$.

Librado P, Rozas J, 2009. DnaSP v5: a software for comprehensive analysis of DNA polymorphism data. Bioinformatics 25: 1451-1452.

Linder HP, de Klerk HM, Born J, Burgess ND, Fjeldså J, Rahbek C. 2012. The partitioning of Africa: statistically defined biogeographical regions in sub-Saharan Africa. J. Biogeogr. 39: 1189-1205.

Marks BD, 2010. Are lowland rainforests really evolutionary museums? Phylogeography of the green hylia (Hylia prasina) in the Afrotropics. Mol. Phylogenet. Evol. 55: 178-184.

Matzke NJ. 2014. Model selection in historical biogeography reveals that founder-event speciation is a crucial process in island clades. Syst. Biol. 63: 951-970.

Miller MA, Pfeiffer W, Schwartz T., 2010. Creating the CIPRES Science Gateway for inference of large phylogenetic trees. Proceedings of the Gateway Computing Environments Workshop (GCE), (pp 1-8). LA, New Orleans.

Moore WS, Overton LC, Miglia KJ, 2011. Mitochondrial DNA based phylogeny of the woodpecker genera Colaptes and Piculus, and implications for the history of woodpecker diversification in South America. Mol. Phylogenet. Evol. 58: 76-84.

Moore WS, Weibel AC, Agius A, 2006. Mitochondrial DNA phylogeny of the woodpecker genus Veniliornis (Picidae, Picinae) and related genera implies convergent evolution of plumage patterns. Biol. J. Linn. Soc. 87: 611-624.

Nee S, Mooers A, Harvey PH, 1992 Tempo and mode of evolution revealed from molecular phylogenies. Proc Natl Acad Sci USA 89: 8322-8326.

Newton I, 2003. The speciation and biogeography of birds. Academic Press, London. 
Nguembock B, Fjeldså J, Couloux A, Pasquet E, 2008. Phylogeny of Laniarius: Molecular data reveal L. liberatus synonymous with $L$. erlangeri and "plumage coloration" as unreliable morphological characters for defining species and species groups. Mol. Phylogenet. Evol. 48: 396-407.

Njabo KY, Bowie RCK, Sorenson MD, 2008. Phylogeny, biogeography and taxonomy of the African wattle-eyes (Aves: Passeriformes: Platysteiridae). Mol. Phylogenet. Evol. 48: 136-149.

Nylander JAA, Ronquist F, Huelsenbeck JP, Nieves-Aldrey JL, 2004. Bayesian phylogenetic analysis of combined data. Syst. Biol. 53: 47-67.

Oatley G, Voelker G, Crowe TM, Bowie RCK, 2012. A multi-locus phylogeny reveals a complex pattern of diversification related to climate and habitat heterogeneity in Southern African White-eyes. Mol. Phylogenet. Evol. 64: 633-644.

Ouellet 1977. Relationships of woodpecker genera Dendrocopos Koch and Picoides Lacépède, (Aves: Picidae). Ardea 65: 165-183

Outlaw RK, Voelker G, Bowie RCK, 2010. Shall we chat? Evolutionary relationships in the genus Cercomela (Muscicapidae) and its relation to Oenanthe reveals extensive polyphyly among chats distributed in Africa, India and the Palearctic. Mol. Phylogenet. Evol. 55: 284-292.

Paradis E, Claude J, Strimmer K, 2004. APE: analyses of phylogenetics and evolution in R language. Bioinformatics 20: 289-290.

Peters JL, 1948. Check-list of the birds of the World, Volume XI. Harvard University Press, Cambridge.

Peters JL, Zhuravlev Y, Fefelov I, Logie A, Omland KE, 2007. Nuclear loci and coalescent methods support ancient hybridization as cause of mitochondrial paraphyly between gadwall and falcated duck (Anas spp.). Evolution 61: 1992-2006.

Pons J, Barraclough TG, Gomez-Zurita J, Cardoso A, Duran DP, Hazell S, Kamoun S, Sumlin WD, Vogler AP, 2006. Sequence-based species delimitation for the DNA taxonomy of undescribed insects. Syst. Biol. 55: 595-609.

Pybus OG, Harvey PH, 2000. Testing macro-evolutionary models using incomplete molecular phylogenies. Proc. R. Soc. B 267: 2267-2272.

R Core Team, 2013. R: A language and environment for statistical computing. R Foundation for Statistical Computing, Vienna, Austria. URL http://www.R-project.org/.

Rabosky DL, 2006a. Likelihood methods for detecting temporal shifts in diversification rates. Evolution 60: 1152-1164. 
Rabosky DL, 2006b. LASER: a maximum likelihood toolkit for detecting temporal shifts in diversification rates from molecular phylogenies. Evolutionary Bioinformatics Online 2:257-260.

Rabosky DL, 2014. Automatic detection of key innovations, rate shifts, and diversitydependence on phylogenetic trees. PLOS ONE 9: e89543.

Rabosky DL, Grundler MC, Anderson CJ, Title PO, Shi JJ, Brown JW, Huang H, Larson JG. 2014. BAMMtools: an $\mathrm{R}$ package for the analysis of evolutionary dynamics on phylogenetic trees. Methods Ecol. Evol. 5: 701-707.

Rambaut A, Suchard MA, Xie D, Drummond AJ, 2014. Tracer v1.6, Available from http://beast.bio.ed.ac.uk/Tracer

Ree RH, Moore BR, Webb CO, Donoghue MJ. 2005. A likelihood framework for inferring the evolution of geographic range on phylogenetic trees. Evolution 59: 2299-2311.

Ree RH, Smith SA. 2008. Maximum likelihood inference of geographic range evolution by dispersal, local extinction, and cladogenesis. Syst. Biol. 57: 4-14.

Reid NM, Carstens BC, 2012. Phylogenetic estimation error can decrease the accuracy of species delimitation: a Bayesian implementation of the general mixed Yule-coalescent model. BMC Evol. Biol. 12: 196.

Ronquist F, Teslenko M, van der Mark P, Ayres D, Darling A, Höhna S, Larget B, Liu L, Suchard MA, Huelsenbeck JP, 2012. MrBayes 3.2: Efficient Bayesian phylogenetic inference and model choice across a large model space. Syst. Biol. 61: 539-542.

Smith BT, McCormack JE, Cuervo AM, Hickerson MJ, Aleixo A, Cadena CD, Pérez-Emán J, Burney CW, Xie X, Harvey MG, Faircloth BC, Glenn TC, Derryberry EP, Prejean J, Fields S, Brumfield RT, 2014. The drivers of tropical speciation. Nature 515: 406-409.

Stamatakis A., 2006. RAxML-VI-HPC: Maximum Likelihood-based Phylogenetic Analyses with Thousands of Taxa and Mixed Models. Bioinformatics 22: 2688-2690.

Stephens M, Donnelly P. 2003. A comparison of Bayesian methods for haplotype reconstruction. Am. J. Hum. Genet. 73: 1162-1169.

Stephens M, Smith NJ, Donnelly P. 2001. A new statistical method for haplotype reconstruction from population data. Am. J. Hum. Genet. 68: 978-989.

Swierczewski EV, Raikow RJ, 1981. Hind limb morphology, phylogeny and classification of the Piciformes. Auk 98: 466-480.

Voelker G, Outlaw RK, Bowie RCK, 2010. Pliocene forest dynamics as a primary driver of African bird speciation. Global Ecol. Biogeogr. 19: 111-121. 
Voelker G, Penalba JV, Huntley JW, Bowie RCK, 2014. Diversification in an Afro-Asian songbird clade (Erythropygia-Copsychus) reveals founder-event speciation via transoceanic dispersal and a southern to northern colonization pattern in Africa. Mol Phylogenet Evol. 73: 97-105.

Voelker G, Huntley JW, Penalba JV, Bowie RCK, 2016. Resolving taxonomic uncertainty and historical biogeographic patterns in Muscicapa flycatchers and their allies. Mol. Phylogenet. Evol. 94: 618-625.

Webb DM, Moore WS, 2005. A phylogenetic analysis of woodpeckers and their allies using 12S, Cyt b, and COI nucleotide sequences (class Aves; order Piciformes). Mol. Phylogenet. Evol. 36: 233-248.

Weibel AC, Moore WS, 2002a. Molecular phylogeny of a cosmopolitan group of woodpeckers (Genus Picoides) based on COI and cyt b mitochondrial gene sequences. Mol Phylogenet Evol 22: 65-75.

Weibel AC, Moore WS, 2002b. A test of a mitochondrial gene-based phylogeny of woodpeckers (Genus Picoides) using an independent nuclear gene, $\beta$-Fibrinogen Intron 7. Mol Phylogenet Evol 22: 247-257.

Wickham H, 2014. scales: Scale functions for graphics. $\mathrm{R}$ package version 0.2.4. http://CRAN.R-project.org/package=scales

Winkler H, Christie DA, 2002. Family Picidae (Woodpeckers). In Del Hoyo J, Elliott A, Sargatal J (Eds), Handbook of the Birds of the World. Volume 7. Jacamars to Woodpeckers. Lynx Edicions, Barcelona, pp. 296-555.

Wolters, H.E., 1975-1982. Die Vogelarten der Erde. Paul Parey, Hamburg and Berlin.

Zimkus, BM, Lawson L, Loader SP, Hanken J, 2012. Terrestrialization, miniaturization and rates of diversification in African puddle frogs (Anura: Phrynobatrachidae). PLoS ONE 7: e35118. 
Table 1. Summary of the species recognized under the BGMYC and 'Phylogenetic' schemes used for the diversification rate analyses.

\begin{tabular}{|l|l|l|l|}
\hline Campethera clade BGMYC & Campethera clade Phylogenetic & Dendropicos clade BGMYC & Dendropicos clade Phylogenetic \\
\hline caroli (including arizela) & caroli & pyrrhogaster & pyrrhogaster \\
\hline herberti & arizela & xantholophus & xantholophus \\
\hline nivosa & nivosa & namaquus & namaquus \\
\hline olivaceus & herberti & stierlingi & stierlingi \\
\hline nubica & olivaceus & obsoletus & obsoletus \\
\hline tullbergii & nubica & elachus & crateri \\
\hline taeniolaema & tullbergii & poecilolaemus & elachus \\
\hline cailliautii & taeniolaema & fuscescens & poecilolaemus \\
\hline bennettii & cailliautii & goertae & fuscescens \\
\hline scriptoricauda & permista & griseocephalus & hartlaubii \\
\hline punctuligera & maculosa & spodocephalus & goertae \\
\hline notata & bennettii & lugubris & griseocephalus \\
\hline abingoni & scriptoricauda & gabonensis & spodocephalus \\
\hline & punctuligera & elliotii & rhodeogaster \\
\hline & balia & abyssinicus & lugubris \\
\hline & notata & & gabonensis \\
\hline & abingoni & & elliotii \\
\hline & mombassica & & johnstonii \\
\hline & & & abyssinicus \\
\hline
\end{tabular}


Table 2. Summary of the biogeographic analyses performed with BioGeoBEARS using the DEC and DEC $+\mathrm{j}$ models. The p- column represents the $\mathrm{p}$-value of the likelihood ratio test. All likelihood ratio tests favoured the DEC $+\mathrm{j}$ model over the DEC model.

\begin{tabular}{|c|c|c|c|c|c|c|c|c|c|c|}
\hline & \multicolumn{3}{|c|}{ DEC } & \multicolumn{3}{c|}{ DEC $+\mathbf{j}$} & $\mathrm{p}$ \\
\hline & $\mathrm{Ln} \mathrm{L}$ & $\mathrm{df}$ & $\mathrm{d}$ & $\mathrm{e}$ & $\mathrm{Ln} \mathrm{L}$ & $\mathrm{df}$ & $\mathrm{d}$ & $\mathrm{e}$ & $\mathrm{j}$ & \\
\hline $\begin{array}{c}\text { Campethera } \\
\text { BGMYC }\end{array}$ & -37.95502 & 2 & 0.04023884 & $1 \mathrm{e}-12$ & -34.64497 & 3 & 0.03034757 & $1 \mathrm{e}-12$ & 0.125822 & 0.01 \\
\hline $\begin{array}{c}\text { Campethera } \\
\text { Phylogenetic }\end{array}$ & -48.41337 & 2 & 0.04049757 & $1 \mathrm{e}-12$ & -40.49906 & 3 & 0.01743798 & $1 \mathrm{e}-12$ & 0.208909 & $7 * 10^{-5}$ \\
\hline $\begin{array}{c}\text { Dendropicos } \\
\text { BGMYC }\end{array}$ & -51.79055 & 2 & 0.08093752 & $3.91^{*} 10^{-2}$ & -44.17915 & 3 & 0.04792962 & $1 \mathrm{e}-12$ & 2.159069 & $9.6^{*} 10^{-5}$ \\
\hline $\begin{array}{c}\text { Dendropicos } \\
\text { Phylogenetic }\end{array}$ & -57.07292 & 2 & 0.0691259 & $2.5^{*} 10^{-8}$ & -52.66273 & 3 & 0.05290496 & $1 \mathrm{e}-12$ & 0.109239 & 0.003 \\
\hline
\end{tabular}


Table 3. Summary of diversification models fitted to the branching times derived from the phylogenies of the genera Campethera and Dendropicos. Analyses were performed on the MCC tree. The name of the best constant and rate variable rate models are given as well as their respective AIC score. $\triangle \mathrm{AICrc:}$ Difference in AIC scores between each model and the overall best-fit model. $\triangle \mathrm{AICrc}$ values in bold indicate significant support for the Rate Variable Model over the Constant Rate Model.

\begin{tabular}{|l|l|l|l|l|}
\hline & Campethera BGMYC & Campethera 'Phylogenetic' & Dendropicos BGMYC & Dendropicos 'Phylogenetic' \\
\hline$\gamma$ & $-2.473(\mathrm{p}=0.007)$ & $-1.283(\mathrm{p}=0.10)$ & $-3.11(\mathrm{p}=0.001)$ & $-2.454(\mathrm{p}=0.007)$ \\
\hline & & & $\begin{array}{l}\text { pureBirth AIC }: \\
5.610082\end{array}$ & pureBirth AIC $:-6.580173$ \\
\hline Best Constant Rate Model & pureBirth AIC $: 8.596885$ & pureBirth AIC $:-6.546504$ & DDL AIC $:-7.411993$ & DDL AIC $:-13.35162$ \\
\hline Best Rate Variable Model & DDL AIC $: 0.4394507$ & DDL AIC $:-7.563502$ & $\mathbf{1 3 . 0 2 2 0 7}(\mathbf{p}=\mathbf{0 . 0 0 2})$ & $\mathbf{6 . 7 7 1 4 4 2}(\mathbf{p}=\mathbf{0 . 0 1 6})$ \\
\hline AICrc & $\mathbf{8 . 1 5 7 4 3 4}(\mathbf{p}=\mathbf{0 . 0 0 8})$ & $1.016998(\mathrm{p}=0.16)$ & \\
\hline
\end{tabular}


Figure 1. Distributions within the Campethera nubica superspecies and the Dendropicos goertae superspecies (Winkler and Christie 2002). Distribution data are from BirdLife International and NatureServe (2013). Maps were made using the R (R CoreTeam 2013) libraries maps and mapdata (Becker and Wilks 2013), maptools (Bivand and Lewin-Koh 2014) and scales (Wickham 2014).

Figure 2. 50\% majority rule consensus tree resulting from the Bayesian partitioned analyses of the concatenated data set (6 partitions; ATP6 $1^{\text {st }}, 2^{\text {nd }}$ and $3^{\text {rd }}$ codon position, MB/GAPDH, BRM). Numbers close to the nodes refer to posterior probabilities and maximum likelihood bootstrap support values greater than 0.95 and 60, respectively. The left panel represents the global phylogeny and the two right trees are the zooms within each genus.

Figure 3. A. 50\% Majority rule consensus tree obtained from the analyses of the three nuclear loci (MB, GAPDH, BRM). B. 50\% Majority rule consensus tree obtained from the analyses of the four loci (MB, GAPDH, BRM, ATP6). Trees were estimated using the algorithm implemented in *BEAST (Heled and Drummond 2010 see Section ). Posterior probabilities are indicated when greater than 0.80 .

Figure 4. Results of the biogeographic analyses using the DEC $+\mathrm{j}$ model as implemented in BioGeoBEARS (Matzke 2014) for the Campethera (18 species) and Dendropicos (19 species) clades assuming the 'Phylogenetic' number of species. Ranges at nodes represent the most likely ancestral range. Pie charts next to the nodes represent the probability of each ancestral area. Areas codes are slightly modified from Linder et al. (2012); see text for details.

Figure 5. Results of the BAMM analyses (above) for the Campethera and Dendropicos clades and the corresponding Log-lineages Through Time Plot (below) under the 'Phylogenetic' scheme for the number of recognized species. The analyses indicate a continuous decrease in diversification rate. The scale bar to the left of the chronograms represents the diversification rate. Numbers next to nodes represent the clades posterior probabilities from the chronogram (Supplementary Figure 6). Solid circles in the Log-lineages Through Time Plot plots indicate the species splits that were recognized under the 'Phylogenetic' species recognition scheme in our study relative to the presently accepted species-level taxonomy (Dickinson and Remsen Jr 2013). Asteriks next to species names indicate lineages that were not recognized as species in the BGMYC analyses. The open 
circles indicate the shape of the Log-lineages Through Time Plot under the BGMYC species recognition scheme. 

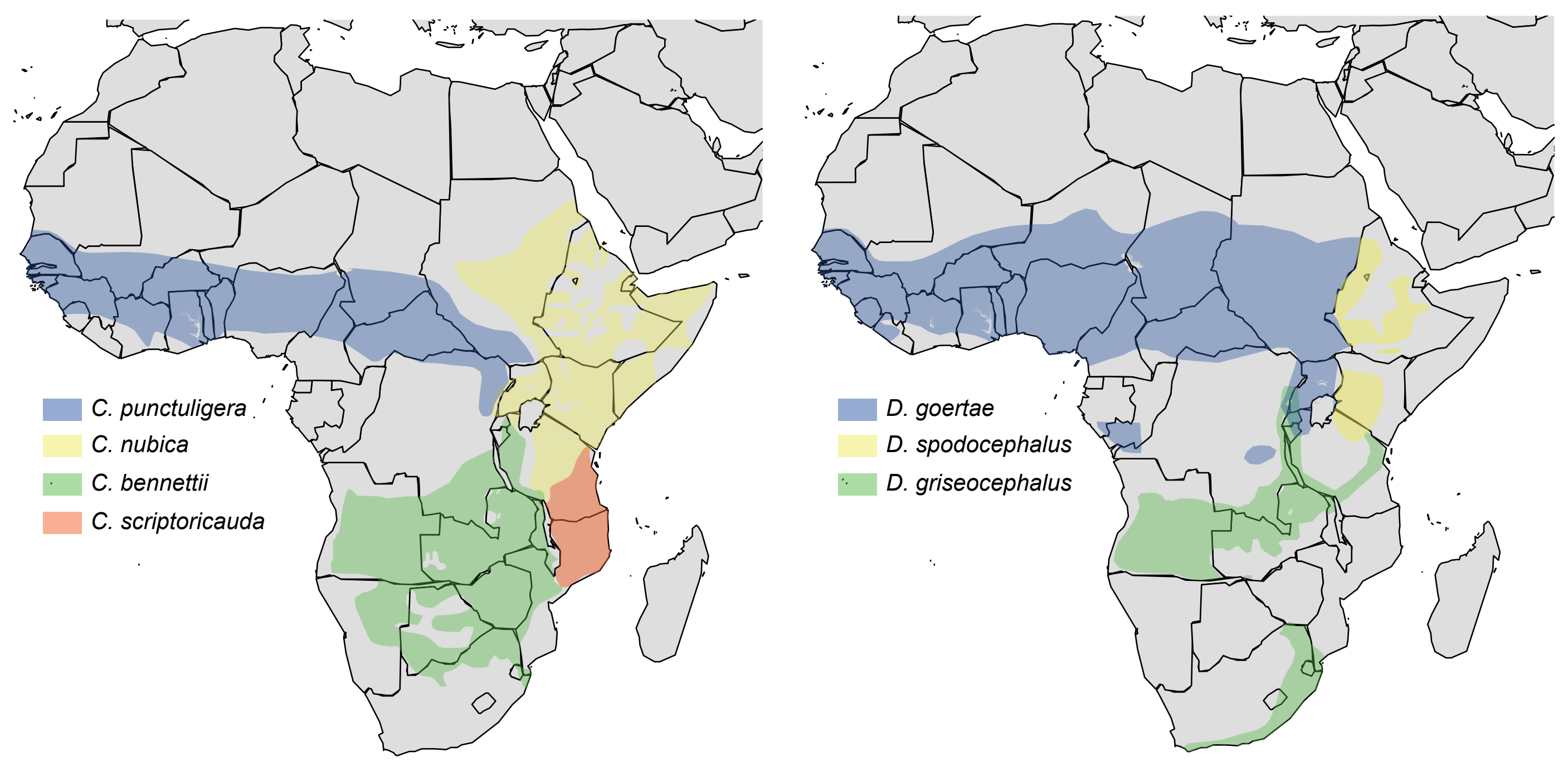


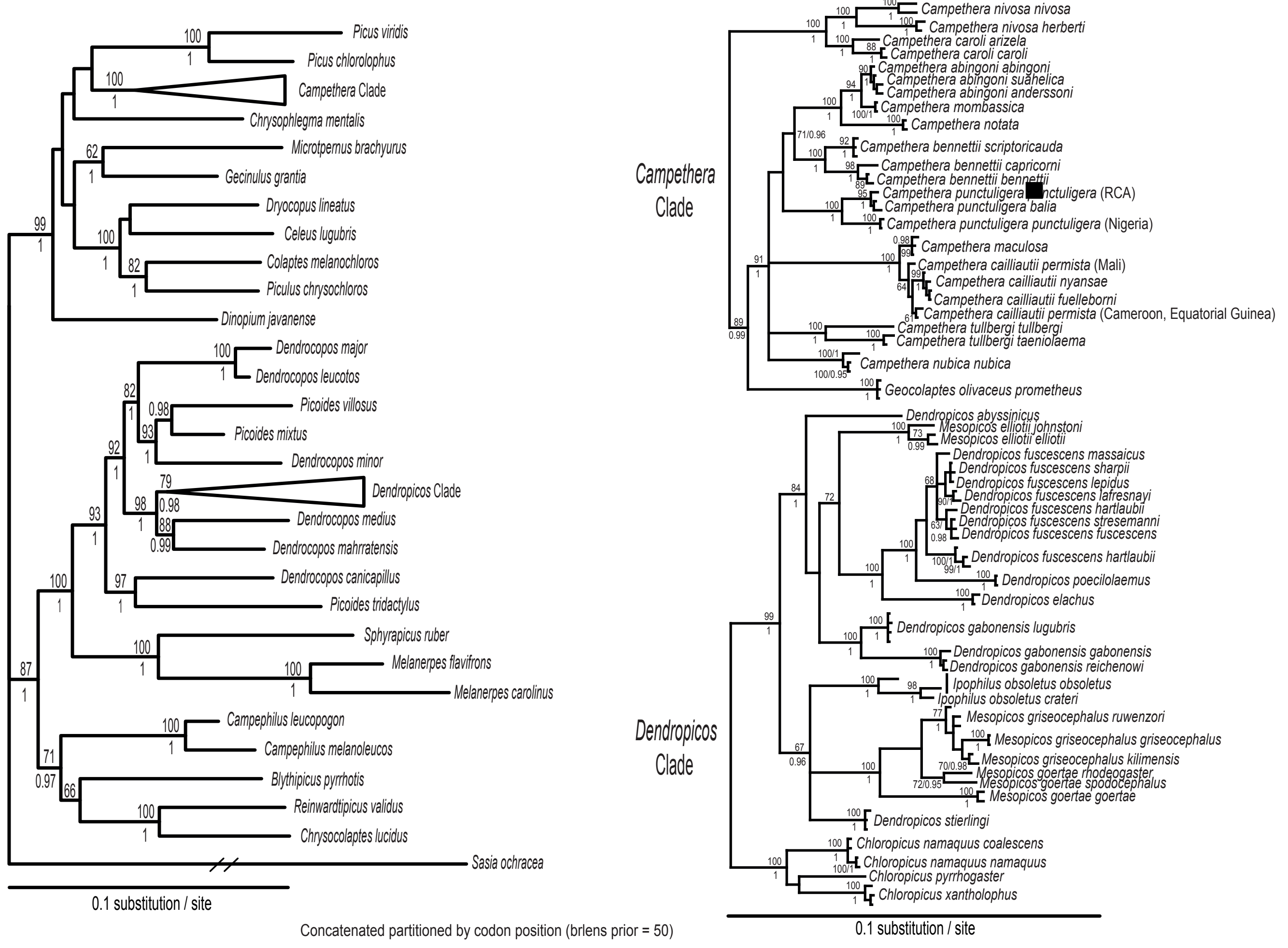




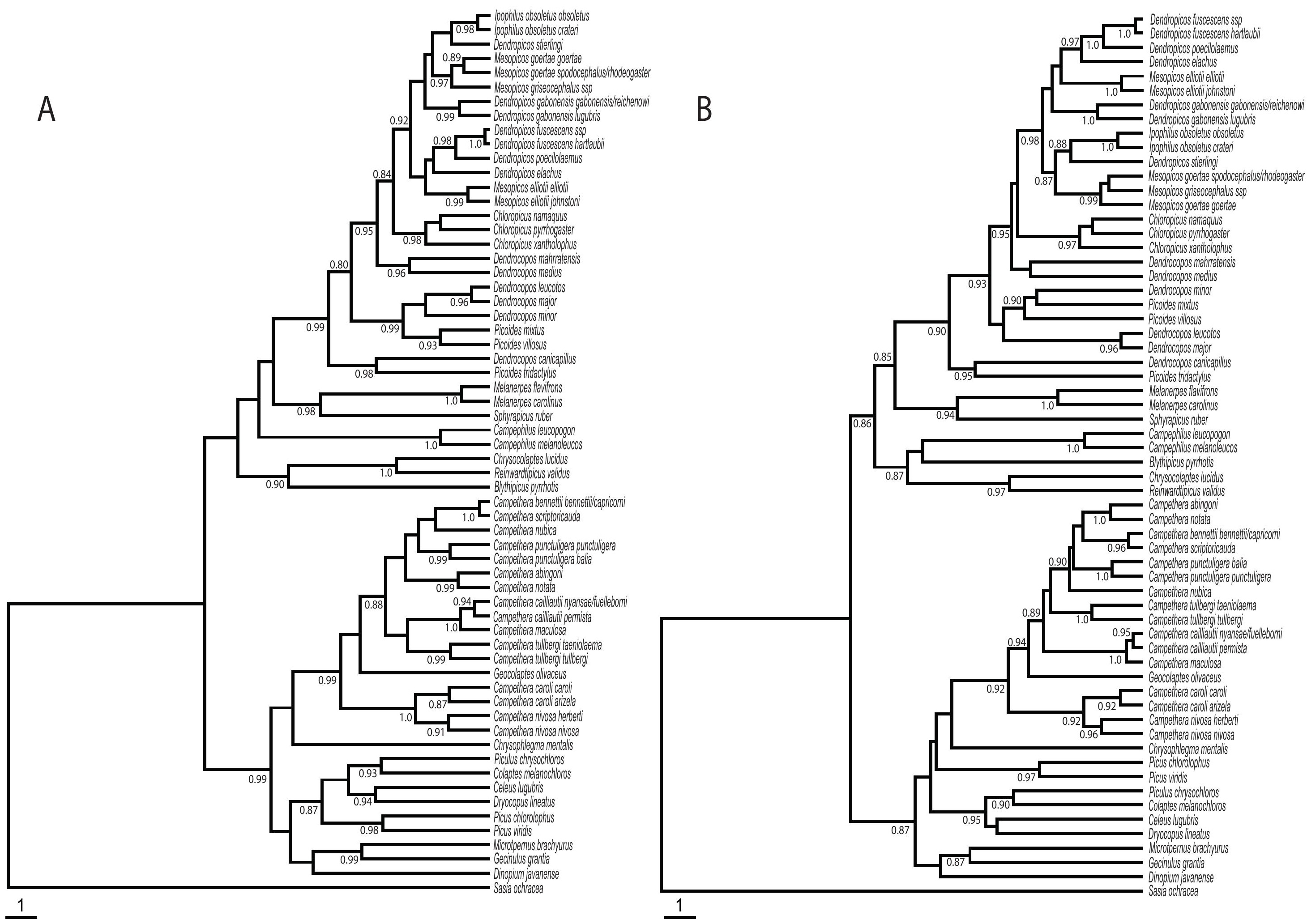



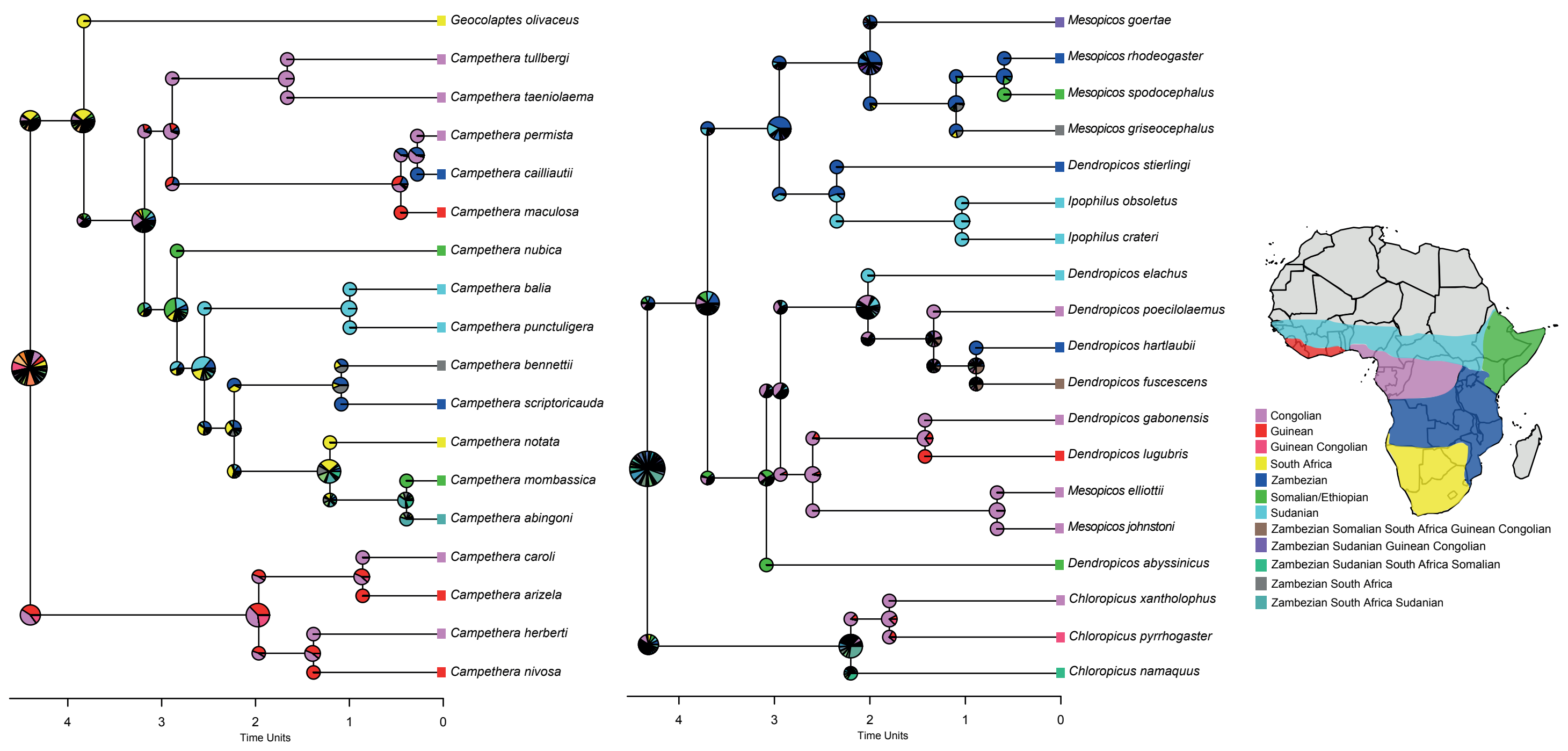


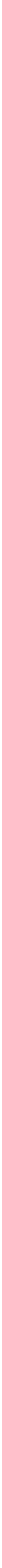




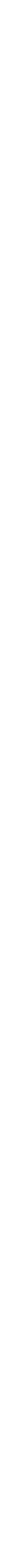

